\title{
Charles Baudelaire e a arte da memória
}

\author{
Roberta Andrade do Nascimento
}

\section{O historiador anacrônico}

Diante de uma imagem - por mais antiga que seja -, o presente jamais cessa de se reconfigurar [...]. Diante de uma imagem - por mais recente, por mais contemporânea que seja -, o passado, ao mesmo tempo, jamais cessa de se reconfigurar, porque essa imagem só se torna pensável em uma construção da memória.*

Em seu livro Devant le temps. Histoire de l'art et anachronisme des images, Georges Didi-Huberman destaca a especificidade do tempo que constitui a obra de arte, defendendo a idéia de que a imagem ${ }^{1}$ deflagra múltiplos elos com base nos quais será possível reconfigurar diversos presentes; nesse sentido, a obra revela a memória que traz consigo, memória essa que continuará, em seu devir, a atravessar outros presentes, uma vez que "sempre, diante da imagem, estamos diante de tempos. [...] olhá-la significa desejar, esperar, estar diante do tempo"*. Nesse contexto, o autor propõe interrogar, de maneira crítica, o tempo que compõe a obra de arte, visto que estamos diante de um presente que não cessa de se restabelecer pela experiência dialética do olhar.

Para realizar esse trabalho arqueológico, é preciso considerar o anacronismo, recusado pelos historiadores ${ }^{2}$, como um

${ }^{1}$ Neste artigo, imagem pode adquirir o sentido amplo de obra de arte. Assim, a obra de arte pode ser vista como um sítio a ser explorado; a cada escavação, camadas do tempo são expostas, revelando a trama que as liga.

${ }^{2}$ Muitos historiadores defendem a idéia de que os fatos são justificados pela referência a uma época determinada. Nesse contexto, cabe ao historiador evitar projetar sua própria realidade sobre as realidades do passado; essa atitude permitiria o acesso à atmosfera mental da época e, conseqüentemente, à compreensão da obra em sua totalidade. Para o historiador, o anacronismo é a intrusão de uma
"(Didi-Huberman, Georges. Devant le temps. Histoire de l'art et anachronisme des images. Paris: Minuit, 2000: 10). 
mecanismo que atravessa todas as contemporaneidades. Pode parecer uma atitude paradoxal, mas não se trata apenas de interrogar o objeto de estudo; trata-se de fazer uma crítica aos valores de uso do tempo: "significa, portanto, interrogar, diante da história da arte, o objeto 'história', a própria historicidade”, ou seja, significa não aceitar a regularidade, o valor como atemporal. Ao se contestar o postulado da concordância dos tempos, admite-se o fato de que o anacronismo é importante a partir do momento em que o passado começa a se revelar insuficiente à sua própria compreensão; admite-se, ainda, que há em cada obra uma tensão provocada pela coexistência de tempos genealógicos heterogêneos. Nesse sentido, diante de uma questão que não pode mais ser explicada pelos aparatos pertencentes ao tempo no qual a obra foi produzida, não há como fugir ao anacronismo, pois ele é um mecanismo que obriga a rever as redes de leitura, apontando para o sentido de decomposição do tempo e denunciando a complexidade temporal inerente à constituição da obra. $\mathrm{O}$ artista é anacrônico quando põe em cena a tensão infinita que existe nos objetos.

Um jogo de montagem de tempos heterogêneos cria os efeitos de anacronismo que um crítico-artista como Charles Baudelaire expõe em suas produções. Porque o artista, mais ou menos conscientemente, manipula seu tempo e os tempos que não são mais os seus, a arte deve ser vista sob o ângulo da memória, que permite ver a obra de arte como um objeto policrônico. Assim sendo, "é preferível reconhecer como uma riqueza a necessidade do anacronismo: ela parece interna aos objetos - às imagens - com as quais tentamos fazer a história. $\mathrm{O}$ anacronismo seria, assim, numa primeira aproximação, a forma temporal de expressar a exuberância, a complexidade e a sobredeterminação das imagens"*.

A obra, então, é observada como uma forma em perpétua transformação, uma montagem de tempos que revela um paradigma teórico próprio; nele, a temporalidade passa a ser vista à luz de um procedimento crítico que tem como base a idéia de uma dialética aberta, em espiral. A dinâmica da me-

época na outra. Em contrapartida, parece inevitável interpretar o passado sem fazer uso do nosso próprio presente. Como penetrar no universo mental fabricado por uma outra época? Como escapar de compreender o presente, ignorando o futuro? O anacronismo, portanto, é um paradoxo que precisa ser assumido. 
mória atua como o princípio ativo dessa montagem, ela investiga as correlações e os diálogos existentes entre os tempos presentes da/na obra, entrelaçando seus fios. Segundo Didi-Huberman, é a memória, anacrônica em seus efeitos de reconstrução do tempo, que é convocada e interrogada pelo historiador, e não exatamente o passado; nesse contexto, o tempo passado só existe como fato de memória: suas características são retiradas por intermédio de um processo de decantação sempre atualizado em um presente, fazendo com que ele ganhe uma fisionomia. A memória, então, “decanta o passado de sua exatidão. É ela que humaniza e configura o tempo, entrelaçando suas fibras [...]. É a memória que o historiador convoca e interroga, não exatamente 'o passado"*.

Nesse sentido, o anacronismo é um mecanismo dialético, pois supõe sempre uma tensão entre os diversos modelos de tempo. Ele indica que em cada presente várias dimensões temporais se relacionam, que em cada obra há uma fusão de diversos tempos genealógicos.

O conceito de anacronismo desenvolvido por Didi-Huberman dialoga intensamente com a atividade teórica de Walter Benjamin; seu trabalho teórico é visto como um pensamento anacrônico, pois resiste ao modelo temporal do historicismo. Em Benjamin, é possível ler as obras como montagens de tempos diferentes, o que significa dizer que uma outra forma de repensar as relações entre o agora e o não mais agora é anunciada por meio de um novo modelo de temporalidade. Nesse novo modelo, a memória entra como elemento importante de um novo pensamento sobre a história, vista não mais como representação do passado, e sim como apresentação. Graças ao conceito de memória, é possível trabalhar no campo da apresentação como construção a partir do presente, tempo que possibilita a deflagração de correlações passadas. O historiador se identifica então com a figura do arqueólogo; nesse trabalho arqueológico, a imagem aparece no centro da vida histórica por se constituir como um objeto dialético, produtor de uma historicidade anacrônica.

A imagem representa, pois, o espaço onde se encontram o agora e o não mais agora, ela é sempre carregada de tensões que o historiador desperta a partir de seu presente. O choque desses tempos genealógicos produz a história, "na imagem, o ser se desagrega: explode e [...] mostra - mas por 
* "A uma passante". Em: Baudelaire, Charles. As Flores do mal. Tradução e notas de Ivan Junqueira. Rio de Janeiro: Nova Fronteira, 1985: 345 .)

"("Àune passante". Em: Bau. delaire, Charles. Lesfleurs du mal. Paris: Librairie Géné rale Française, 1972: 162).

* (Seligmann-Silva, Márcio. "Reflexões sobre a memória, a história e o esqueci. mento". Em: Seligmann Silva, Márcio (org). História, memória e literatura: o tes temunho na era das catás. trofes. Campinas: Unicamp, 2003: 70). muito pouco tempo - de que é feito. A imagem não é a imitação das coisas, mas um intervalo traduzido de forma visível, a linha de fratura entre as coisas"*. Nesse contexto, o culto das imagens deve ser compreendido pelo seu poder de síntese e apreciação. A arte é vista como imagem que garante ao olhar a possibilidade de existência. Essas reflexões, de certa forma, já estão presentes no trabalho de Charles Baudelaire; nele, é marcante o fascínio pelas imagens:

Que luz... e a noite após ! Efềmera beldade Un éclair... puis la nuit! - Fugutive beauté

Cujos olhos me fazem nascer outra vez, Dont le regard m'a fait soudainement renaître,

Não mais hei de te ver senão na eternidade? Ne te verrai-je plus que dans l'éternité?

Longe daqui! tarde demais! Nunca talvez! Ailleurs, bien loin d'ici! trop tard! jamais peut-être!

Pois de ti já me fui, de mim tu já fugiste, Car j’ignore où tu fuis, tu ne sais où je vais,

Tu que eu teria amado, ó tu que bem o viste!" Ô toi que j’eusse aimée, ô toi qui le savais!"

Como passantes, elas se substituem veloz e infinitamente; o poeta trabalha, pois, com imagens múltiplas em um campo paradoxal porque une eterno e transitório no mesmo espaço.

O movimento de ir e vir por entre essas temporalidades constrói um texto aberto que demanda a construção de uma completude e, ao mesmo tempo, aponta para sua impossibilidade; essa dinâmica traz à tona os diversos presentes da obra por meio do presente do historiador/crítico/artista, através de uma leitura que opera por anacronismos, uma vez que concebe a experiência do tempo como um espaço repleto de "agoras". Nesse sentido, o que é inexorável é a mudança acarretada pelo devir do presente.

Nesse espaço (de tempo) há construção e reconstrução, montagem de tempos heterogêneos, montagem essa que será reivindicada como construção da memória, processo por intermédio do qual se produz o conhecimento. Nesse sentido, Benjamin "afirma que o historiador materialista - ou seja, antihistórico - deve visar à construção de uma montagem: vale dizer, de uma collage de escombros e fragmentos de um passado que só existe na sua configuração presente de destroço"**

Entende-se, pois, que um novo ponto de vista exige a elaboração de novos modelos de tempo. O saber é posto em 
movimento, sustentado pela esperança de recomeços, escapando do modelo do passado fixo. $\mathrm{O}$ modelo dialético recusa a idéia de continuidade, é da descontinuidade da história que se deduz o seu caráter inacabado. $\mathrm{O}$ passado é visto não mais como "um passado eterno", mas como fato em movimento, fato de memória, que evoca os acontecimentos e os constrói no saber presente do historiador, apontando para a importante existência de uma teoria da memória.

O historiador é o trapeiro da memória das coisas, seu trabalho se fundamenta na análise de rastros; para ele, tudo é anacrônico. Nesse sentido, pode-se defender a idéia de que todos os tempos genealógicos coexistem no mesmo presente; as obras não fazem parte de um passado desaparecido, são matéria que sobrevive. No momento de crise provocado pela coexistência dessas diversas temporalidades, o trabalho da memória é deflagrado. Logo, a memória é processo, movimento dialético desencadeado pelo presente do historiador. É importante, nesse contexto, destacar que, para Benjamin, o tempo presente é um espaço repleto de "agoras”, que “a história é objeto de uma construção cujo lugar não é o tempo homogêneo e vazio, mas um tempo saturado de 'agoras"*. Como historiador moderno, Baudelaire se abre ao trabalho da memória e enfatiza sua importância.

O que é o cérebro humano senão um palimpsesto imenso e natural? Meu cérebro é um palimpsesto e o seu também, leitor. Inúmeras camadas de idéias, de imagens, de sentimentos caem sucessivamente sobre seu cérebro, tão docemente como a luz. Pareceu que cada uma sepultava a precedente. Mas nenhuma, na realidade, pereceu.
Qu'est-ce que le cerveau humain, sinon un palimpseste immense et naturel? Mon cerveau est un palimpseste et le vôtre aussi, lecteur. Des couches innombrables d'idées, d'images, de sentiments sont tombées successivement sur votre cerveau, aussi doucement que la lumière. Il a semblé que chacune ensevelissait la précédente. Mais aucune en réalité n'a péri.
*(Benjamin, Walter. Magiae técnica, arte e política. Tradução de Sérgio Paulo Rouanet. São Paulo: Brasi. liense, 1985: 229.)

" "Un mangeur d'opium". Em: Baudelaire, Charles. Oeuvres complètes. Paris: Robert Laffont, 1980: 297-8).

Para a literatura que trabalha com a memória, o que gera uma tensão dialética é o fato de trabalhar simultaneamente com a necessidade do lembrar-se e com a sua impossibilidade.

A teoria da história de Benjamin é uma teoria da memória. "Benjamin reafirmou a força do trabalho da memória: que a um só tempo destrói os nexos (na medida em que trabalha a 
" (Seligmann-Silva, Márcio. "Catástrofe, história e memória em Walter Benja min e Chris Marker: a escritura da memória". Em: Seligmann-Silva, Márcio (org). História, memória e literatura: o testemunho na era das catástrofes. Ob. cit.: 393),

*(Gagnebin, Jeanne Marie. História e narração em Walter Benjamin. São Paulo: Pers pectiva, 1999: 14).

"(Ibid.: 11)

"(Didi-Huberman, Georges. Devant le temps. Histoire de l'art etanachronisme des ima. ges. Ob. cit.: 242). partir de um conceito forte de presente) e (re)inscreve o passado no presente"*. Para ele, a história está colocada em termos de origem, e a origem em termos de novidade. Isso porque a origem se constitui como uma dinâmica presente em cada objeto histórico; seu movimento é duplamente articulado: de um lado, é restauração, reconstituição (do que foi destruído); de outro, algo aberto, inacabado; ela é objeto dialético, representa um salto para fora da sucessão cronológica, quebrando, pois, a linha do tempo, obrigando, a cada vez, a reorganizar a memória.

O movimento de restauração "indica, portanto, de maneira inelutável, o reconhecimento da perda, a recordação de uma ordem anterior e a fragilidade dessa ordem"*. Dessa maneira, a origem é também anacronismo, pois trabalha com a novidade e a repetição: o inacabamento e a abertura são as condições que tornam possível o seu desdobramento. O conceito de origem permite visualizar o estabelecimento de uma nova ligação entre o passado e o presente, ou seja, "história e temporalidade não são, portanto, negadas, mas se encontram, por assim dizer, concentradas no objeto: relação intensiva do objeto com o tempo, do tempo no objeto, e não extensiva do objeto no tempo, colocado como por acidente num desenrolar histórico heterogêneo à sua constituição"*

Didi-Huberman analisa a aura como um modelo temporal capaz de dar conta da origem, capaz de dar conta dos acontecimentos da memória. Dessa forma, a aura é designada como imagem dialética, produtora de uma leitura crítica de seu próprio presente, um modelo temporal aberto em que se encontram o agora e o não mais agora; um modelo temporal que se constitui sem configurar um sistema dogmático, pois não resolve as contradições nem promove a síntese. Há nisso um parâmetro crítico que revela, na imagem dialética, uma capacidade aguda de intervenção teórica. Dessa maneira, "produzir uma imagem dialética significa convocar o ontem, aceitar o choque de uma memória, recusando se submeter ou retornar ao passado [...] significa criticar a modernidade (o esquecimento da aura) por um ato de memória, e, ao mesmo tempo, criticar o arcaísmo (a nostalgia da aura) por um ato de invenção, de substituição, de des-significação essencialmente modernos"*

Ao se valorizar o "agora", valoriza-se a abertura como condição de atualização do passado; a rememoração de imagens 
guardadas na memória atualiza os momentos presentes e instaura uma nova forma de se relacionar com a obra, que ganha sentido a partir das interferências das épocas evocadas. A cada atualização, novo retorno à origem. A cada origem que se estrutura ocorre um confronto incessante entre uma idéia e o mundo histórico; desse confronto, ocorre a descoberta do agora, momento-espaço em que se forma a consciência que provoca transformação.

O agora é uma manifestação autônoma da atualidade, uma produção que se constrói de forma eloqüente a partir do entrecruzamento de manifestações passadas e presentes, o que torna cada vez mais difícil determinar as marcas que caracterizam presente, passado e aspirações ao futuro. À medida que novas crises se instauram, a obra se transforma em outra. Esse movimento permite a reconstituição de vários presentes que se fundem para compor um outro presente, que resiste como forma e, ao mesmo tempo, reclama outras formas.

Nesse sentido, entre o historiador e seu objeto não há distância, o historiador sempre trabalhará com as ruínas, expondo os cacos que se transformam em imagens da memória. Como ruína, a memória é movimento que comporta em si espaço e tempo, é seleção-esquecimento, ou seja, consciência da transformação - “doravante hás de ser, ó pobre e humano escombro!"*.

O trabalho da memória se inscreve como um desdobramento infinito, culto paradoxal do presente, combate, esboço, arte de um instante pleno. Nesse contexto, é importante atentar para a singularidade da obra, conseqüência da singularidade do instante. Por isso, a obra pode ser considerada imagem-origem, pois é, a cada vez, uma nova imagem, é tempo e movimento.

\section{O pensador alegórico}

A historiografia narra as ruínas de seu tempo, “ruinas representam aqui justamente a síntese paradigmática entre tempo e espaço; a ruína é uma imagem-tempo"*. A destruição do presente na ruína é representada fortemente pela teoria da alegoria. Para Benjamin, a alegoria está ligada a uma "reabilitação da temporalidade e da historicidade em oposição ao ideal que o símbolo encarna"; nesse sentido, pode-se pensar a alegoria em contraposição à idéia de passado eterno, o que
* "désormais tu n'es plus, ô matière vivante!" (Baude. laire, Charles. "Spleen". Em: Asflores do mal. Ob. cit.: 293.)

"(Seligmann-Silva, Márcio. "Catástrofe, história e memória em Walter Benja. min e Chris Marker: a escritura da memória". Ob. cit.: 394-5).

"(Gagnebin, Jeanne Marie. História e narração em Walter Benjamin. Ob. cit.: 31 ). 
"(Ibid.:38)

"(Baudelaire, Charles. "Uma carniça". Em: As Flores do mal. Ob. cit.: 175 , Grifo meu.)

"(Baudelaire, Charles. "Une charogne". Em: Lesfleurs du mal. Ob. cit.: 30.)

* Seligmann-Silva, Márcio. "Catástrofe, história e memória em Walter Benjamin e Chris Marker: escritura da memória". Ob. cit.: 396-7.)

*(Cf. Hirt, André. Baudelaire. L'exposition de la poésie. Paris: Kimé, 1998: 149.) determina uma outra compreensão da história, pois o sentido da totalidade se perde a partir do momento em que um pólo duradouro deixa de existir, anunciando a fragmentação/desintegração daquilo que parecia uno. Na alegoria, está presente a tensão entre duas forças que coexistem: eternidade e transitoriedade, ela "ressalta a impossibilidade de um sentido eterno e a necessidade de perseverar na temporalidade e na historicidade para construir significações transitórias"*, como se pode observar no seguinte excerto de um poema de Baudelaire:

As formas fluíam como um sonho além da vista, Les formes s'effaçaient et n'étaient plus qu'un rêve,

Um frouxo esboço em agonia, Une ébauche lente a venir,

Sobre a tela esquecida, e que conclui o artista Sur la toile oubliée, et que l'artiste achève

Apenas de memória um dia. Seulement par le souvenir.

A alegoria pode ser interpretada também como uma operação crítica ${ }^{3}$ de apropriação deformadora, um "exercício de ressignificar infinitamente o mundo [...]. A alegoria baudelairiana [...] nasce do sentimento de transitoriedade que é radicalizado com o advento da cidade moderna"*, ela confere, no presente, a presença*. Nesse sentido, o trabalho do poeta se configura como autodestruição criadora, uma imagem nunca acabada - a memória do presente. A cidade se transforma em ruína, a forma muda rapidamente, e tudo se transforma em alegoria, como diz o poeta no poema "Le cigne"; o culto das imagens em Baudelaire se deve à consciência da efemeridade eterna das coisas, da destruição permanente, da presença do sentimento de "agoridade", momento em que o tempo passa a ser compreendido como um espaço de passagem e seu trabalho se inscreve na irreversibilidade do tempo. Segundo André Hirt, é a singularidade de uma beleza alegórica que Baudelaire define como modernidade.*

${ }^{3}$ Vale lembrar o diálogo entre os conceitos de crítica de Benjamin e de Baudelaire. Para Benjamin, a "crítica é, então, como que um experimento na obra de arte, através do qual a reflexão desta é despertada e ela é levada à consciência e ao conhecimento de si mesma”, ou seja, a crítica é o desdobramento da reflexão como processo através do qual a arte tem a possibilidade de se multiplicar. Cf. Benjamin, Walter. $O$ conceito de crítica de arte no romantismo alemão. São Paulo: Iluminuras, s/d: 74. Em Baudelaire, a crítica é uma mnémotechnie du beau, ela assegura a representação de uma textura temporal singular, teorizando sobre como o presente se apresenta, pensando a época e respondendo a suas demandas. Cf. Baudelaire, Charles. Critique d'art suivi de critique musicale. Paris: Gallimard, 1976. 
A alegoria é, portanto, uma trama complexa que impede a cristalização do sentido; nesse contexto, a imagem alegórica é vista como possibilidade de construção do conhecimento, pois convoca os vestígios do passado, trabalhando-os de maneira crítica para ultrapassá-los dialeticamente à luz de um olhar situado no presente. $\mathrm{O}$ anacronismo, que só se torna pensável a partir da consciência da multiplicidade, ligase ao conceito benjaminiano de alegoria no sentido de apontar para uma tensão temporal, para uma operação que nasce do sentimento de destruição permanente, para uma memória que se reconfigura incessantemente.

Dessa maneira, pode-se dizer que sempre há uma reformulação de problemas que parte do interior da própria obra, negando-se a eterna consecução de causas, pois a obra de arte possui uma temporalidade específica que interroga e reinventa, constrói e desconstrói a história da arte valendose da história da própria obra de arte: a obra de arte moderna é consciente de si como montagem, como impossibilidade de representar uma totalidade. Para Walter Benjamin, a história da arte está sempre a recomeçar, pois cada nova reflexão conduz novamente à origem, podendo-se dizer, nesse sentido, que ela é o resultado da tensão entre Erfahrung e Erlebinis. ${ }^{4}$ Essa tensão resulta em um processo irônico que entrelaça lembrança e esquecimento, dialética sem síntese possível; Baudelaire é irônico no sentido de perceber esse paradoxo. Sua ironia é compreendida como "forma específica e apurada de auto-reflexão que afirma a imbricação essencial entre a construção da obra (cuja possibilidade de existência individual é a limitação formal), sua necessária auto-superação (pois toda obra verdadeira visa a ser mais do que ela mesma para se abrir à idéia absoluta da arte) e, portanto, sua autodestruição"*.

A ironia de Charles Baudelaire, que se abre ao trabalho da memória, revela-se a partir da destruição de seu próprio objeto de trabalho e da reestruturação de seu aspecto formal. A ironia perpassa todo o trabalho do crítico-poeta, ela representa a consciência do inacabamento, a aspiração à to-

${ }^{4}$ A experiência da arte em Baudelaire pode ser pensada a partir de uma relação dialética entre a experiência resultante da acumulação da memória e a experiência vivida. Cf. Hirt, André. Il faut être absolument lyrique. Une constellation de Baudelaire. Ob. cit.
* (Gagnebin, Jeanne Marie. "Nas fontes paradoxais da crítica literária. Walter Benja. min relê os românticos de Jena". Em: Seligmann-Silva Márcio (org.). Leituras de Walter Benjamin. São Paulo: Fapesp/Annablume, 1999: 76). 
" (Hirt, André. Baudelaire. L'exposition de la poésie. $\mathrm{Ob}$. cit.: 146).

"(Hofmann, Werner. "Baude laire et la caricature", Preu ves, n. 267: Baudelaire et la critique d'art, mai 1968: 38)

(Cf. Laforgue, Pierre. Ut pictura poesis. Baudelaire: la peinture et le romantisme. Lyon: Presses Universitaires de Lyon, 2000). talidade e o fracasso dessa busca. Nesse universo, o esboço é a figura da passagem, consciência da impossibilidade de apreender qualquer figuração, pois sempre há um atraso em relação à representação da experiência: para o autor de Salon de 1859, a forma é o que está vindo a ser. Nesse contexto, "a memória, em Baudelaire, não opera de forma linear, justaposta e cumulativa. Ela possui uma força crítica que rompe toda continuidade mecânica. [...] Não é uma transcrição do passado no presente, mas uma descontextualização do passado no seio do presente"*.

\section{A memória do presente}

Entre construção e desconstrução, temporalidades heterogêneas trabalham. O tempo presente em Baudelaire é considerado como origem porque rompe o curso da história, elaborando imagens que circulam em um tempo aberto; cada imagem que aparece nesse processo de substituição já surge com o espectro de sua ruína. Segundo Werner Hofmann, “a descoberta do presente se apóia necessariamente sobre uma observação complementar: a descoberta do passado. Quem adota uma dessas duas perspectivas deve aceitar a outra”*

$\mathrm{O}$ autor de Les Fleurs du Mal articula um duplo regime temporal: o agora e o não mais agora, manipulando seu tempo e os tempos que não são mais os seus de forma dialética. Essa manipulação cria novas formas a cada movimento; essas formas se juntam às anteriores e se reconstroem das ruínas, meio através do qual se pode visualizar a passagem do tempo.

O poeta de Spleen de Paris entende o tempo não como presente, mas como consciência do tempo presente, consciência imediata da ausência; por isso, tenta salvá-lo. A salvação do presente se dá pela aceitação de uma dupla relatividade: histórica e estética do belo. Baudelaire inscreve seu pensamento no contexto histórico*, seu trabalho ganha sentido no seio de uma problemática histórica, ou seja, a partir da consciência do tempo presente em sua temporalidade de presente. Ele não ignora a história, é sua consciência imediata, e por isso seu objetivo maior é exaltar a atualidade. "A atitude de Baudelaire implica, novamente, em uma inversão da perspectiva tradicional. Outrora, o passado, considerado depositário do eterno, definia o presente, e ele o definia estritamente: a criação artística era uma imitação dos arquétipos fornecidos 
pela arte antiga ou pela própria natureza. Hoje, o eterno depende do presente: este é, de um lado, uma crítica da tradição que, a cada momento, refuta a eternidade, transformando-a em novidade transitória; de outro, o eterno não é um, mas múltiplo"**.

A obra de Charles Baudelaire exprime a estrutura dialética da imagem, a dialética da temporalidade que ela contém, é uma composição de imagens, apresenta um conjunto de idéias que se metamorfoseiam. É a partir desse movimento de transformação, de metamorfose, que a forma pode ser concebida como originária, pois a origem é a crítica do presente; é no agora que a origem aparece. Essa montagem/desmontagem de singularidades está inserida em um contexto que interroga a estrutura do tempo. A variação representada pela metamorfose, pela multiplicidade e a coexistência dessa multiplicidade são algumas das características encontradas nos textos em verso e em prosa de Baudelaire. Seu trabalho reside na singularidade irredutível de um processo que engendra um pensamento em outro e refuta o exato.

Em Les fleurs du mal, há corte e montagem em um determinado "agora". Nesse sentido, o livro de poemas pode ser considerado uma topografia da memória; nele, tudo é (re)descoberto pelo trabalho de escavação da memória que parte do presente do poeta, pois "é no presente que convivem as imagens que se entrecruzam, se refletem e se apagam novamente"* A memória não absorve a exatidão, mas a impressão causada pelo objeto, como escreve Baudelaire em Le Peintre de la vie moderne: "todos os bons e verdadeiros desenhistas desenham conforme a imagem escrita em seu cérebro, e não conforme a natureza"; o uso da memória implica em uma forma especial de registro, pois ela traduzirá essas impressões.

A arte mnemônica passa pela mediação da memória e da imaginação: uma série de impressões é armazenada para depois se transformar em imagem, é uma luta contra o tempo, que só pode ser detido pela força da memória; ela é, portanto, a matriz do pensamento baudelairiano, é "uma escritura da memória [...]: não imagem da memória, mas uma memória da imagem"*.

Para Baudelaire, Constantin Guys encarna essa memória do presente. Nos trabalhos do pintor, assim como nos escritos do poeta de Les fleurs du mal, a obra se transforma
" (Paz, Octavio. "Présence et présent", Preuves, n. 207 Ob.cit.: 9-10).

- Seligmann-Silva, Márcio. "Catástrofe, história e memória em Walter Benja. min e Chris Marker: a escritura da memória". Ob. cit.: 407).

* "tous les bons et vrais des. sinateurs dessinent d'après l'image écrite dans leur cer. veau, et non d'après la na. ture" (Baudelaire, Charles. Critique d'art suivi de critique musicale. Paris: Gallimard 1976: 358).

"(Hirt, André. Il faut être absolument lyrique. Une cons tellation de Baudelaire. Ob. cit.: 59). 
* "perd la mémoire du pré. sent; il abdique la valeur et les privilèges fournis par la circonstance, car presque toute notre originalité vient de l'estampille que le temps imprime à nos sensations." (Baudelaire, Charles. Critique d'art suivi de critique musicale. Ob. cit.: 356)

*(Ibid.: 352).

' (Gagnebin, Jeanne Marie. "Baudelaire, Benjamin e o moderno". Em: Sete aulas sobre linguagem, memória história. Rio de Janeiro: Imago, 1997: 145).

* (Baudelaire, Charles. "As multidões" Em: Pequenos poemas emprosa. Tradução de Aurélio Buarque de Holanda Ferreira. Rio de Janeiro: Nova Fronteira, 1980: 39)

" (Baudelaire, Charles. "Les Foules". Em: Oeuvres complètes. Ob. cit.: 170)

em ruína, a modernidade cria sua própria antigüidade, pois ela é frágil e está fadada à destruição. Sendo assim, o tempo presente se revela importante a partir de uma ameaça constante de desaparecimento. Nesse contexto, o artista que projeta seu olhar somente para trás "perde a memória do presente; abre mão do valor e dos privilégios fornecidos pela circunstância, pois quase toda nossa originalidade vem da marca que o tempo imprime em nossas sensações"*.

No contexto de valorização do presente, o observador se modifica incessantemente, pois uma identidade estanque não permite a renovação da percepção. Nesse sentido, o próprio artista incorpora uma atitude alegórica. Esse movimento contra a acomodação exige que o artista, "homem do mundo", transforme-se constantemente, podendo ser comparado a:

um espelho tão grande quanto essa multidão; um caleidoscópio dotado de consciência, que, a cada um de seus movimentos, representa a vida múltipla e a graça movediça de todos os elementos da vida. É um eu insaciável do $n \tilde{a} o-e u$, que, a cada instante, o traduz e o exprime em imagens mais vivas que a própria vida, sempre instável e fugidia. un miroir aussi immense que cette foule; à un kaléidoscope doué de conscience, qui, à chacun des ses mouvements, représente la vie multiple et la grâce mouvante de tous les éléments de la vie. C'est un moi insatiable du non-moi, qui, à chaque instant, le rend et l'exprime en images plus vivantes que la vie elle-même, toujours instable et fugitive.*

Segundo Jeanne Marie Gagnebin, "uma identidade estanque impediria a flexibilidade necessária a uma constante renovação da percepção. O artista moderno é homem do mundo' e 'homem das multidões' também no sentido profundo de uma dissolução da particularidade na universalidade alheia"*. Ou seja,

o poeta goza do incomparável privilégio de ser, à sua vontade, ele mesmo e outrem. Como essas almas errantes que procuram corpo, ele entra, quando lhe apraz, na personalidade de cada um. Para ele, e só para ele, tudo está vago; e, se alguns lugares parecem vedados ao poeta, é que a seus olhos tais lugares não valem a pena de uma visita.*
Le poète jouit de cet incomparable privilège, qu'il peut à sa guise être lui-même et autrui. Comme ces âmes errantes qui cherchent un corps, il entre, quand il veut, dans le personnage de chacun. Pour lui seul, tout est vacant; et si certaines places paraissent lui être fermées, c'est qu'à ses yeux elles ne valent pas la peine d'être visitées"* 
A busca pelo novo é um processo que domina o artista: ao encontrá-lo, ele logo se transforma em antigo. $\mathrm{O}$ artista se vê condenado a encontrar uma nova forma de olhar, por isso ele muda constantemente, desagrega constantemente sua identidade; ao desagregar-se, armazena em sua memória impressões que se transformarão em imagens. A memória manifestase, pois, na luta contra o movimento implacável do tempo.

A história não é um desenvolvimento orientado pelo progresso, uma sucessão cronológica de fatos, ela é a memória do presente. Nesse sentido, a modernidade em Baudelaire é a memória do presente, pois esse tempo possui existência em si, e não somente em relação ao passado, sendo um modo de olhar permitido pela alteração permanente do mundo. De acordo com Jeanne Marie Gagnebin, "a verdadeira modernidade [de Baudelaire ] consiste em ousar afirmar, ao mesmo tempo e com a mesma intensidade, a força e a fragilidade da lembrança, o desejo de volta e a impossibilidade do retorno, o vigor do presente e a sua morte próxima"*

Baudelaire desenvolve um trabalho crítico em seu livro de poemas: em sua obra, é possível ver rastros de uma outra realidade, pois ela é o esboço de um outro tempo, diante da obra ele busca "analisar os elementos de progresso ou os fermentos de ruína que ela contém em si”, seus textos formam universos autônomos, mas que se imbricam, que interagem, construindo uma unidade a partir da diversidade e a diversidade a partir/dentro da unidade; essa construção geradora de vários sentidos é o resultado da tensão entre o limite e o ilimitado. $\mathrm{O}$ autor de Le Peintre de la vie moderne produz sentidos a partir de uma ausência, de uma ruína, de um esboço que não se sabe se compôs um todo, ele realiza o trabalho de um pensador alegórico, partindo do princípio de que "a história não é, pois, simplesmente o lugar de uma decadência inexorável como uma infinita melancolia poderia nos induzir a crer. Ao se despedir de uma transcendência morta e ao meditar sobre as ruínas de uma arquitetura passada, o pensador alegórico não se limita a evocar uma perda; constitui, por essa mesma meditação, outras figuras de sentido"**

O trabalho de Baudelaire confronta a história e o presente, e esse confronto compõe sua idéia de modernidade - um núcleo de tensão -, conduzindo o homem à consciência de que o presente está sempre ameaçado, de que a modernidade é um
- (Gagnebin, Jeane Marie. História e narração em Walter Benjamin. Ob. cit.: 154).

*"analyser les éléments de progrès ou les ferments de ruine qu'elle contient en elle" (Baudelaire, Charles. Critique d'art suivi de critique musicale. Ob. cit.: 238).

" (Gagnebin, Jeane Marie. História e narração em Walter Benjamin. Ob. cit.: 46). 
esboço, um processo em devir que se funda como afirmação e crise, e se reorganiza permanentemente. A consciência aguda da redução drástica da experiência do tempo imprime, na modernidade, a característica da constituição e da destruição, o que produz a paradoxal sensação de se estar sempre à frente de seu tempo, mas também sempre atrasado em relação à novidade que nos escapa. O paradoxo dessa modernidade consiste no fato de ela ser a um só tempo obcecada pela memória, concebida como criação e conhecimento, e pelo contingente efềmero; nesse sentido, busca aproximar o que está distante e distanciar o que está próximo, retornando ao passado a partir do presente que nos é próprio, ou seja, operando por anacronismo. Esse sentimento traduz a consciência da perenidade do presente e demonstra a importância do trabalho da memória, percebido e desenvolvido pelo autor de Salon de 1859 em sua obra. 


\section{Roberta Andrade do Nascimento}

Doutoranda em Literaturas de Língua Francesa pela Universidade

Federal do Rio de Janeiro.

\section{Resumo}

Análise da noção de memória do presente - dimensão dialética - desenvolvida por Charles Baudelaire em seus textos críticos e poéticos a partir da articulação de um duplo regime temporal que permite pensar a obra de arte como um objeto policrônico. À luz de teóricos como Georges Didi-Huberman e Walter Benjamin, pretende-se examinar como as noções de crítica, anacronismo, alegoria, imagem, ruína, origem e tempo presente dialogam e interagem para constituir núcleos de reflexão.

\section{Abstract}

Analysis of the concept of memory of the present - dialectical dimension - developed by Charles Baudelaire in his critical and poetical texts by means of the articulation of a double time regime, which enables the compreension of a work of art as an object that entails different times. In the light of some authors, such as Georges Didi-Huberman and Walter Benjamin, the aim of this article is to analyse how the notions of critics, anachronism, allegory, image, ruin, origin and present time interact in order to create reflection nuclei.

\section{Résumé}

Analyse de la notion de mémoire duprésent-dimension dialectique - développée par Charles Baudelaire dans ses textes critiques et poétiques à partir de l'articulation d'un régime temporel double qui permet de voir l'oeuvre d'art comme un objet polichronique. À la lumière de théoriciens comme Georges DidiHuberman et Walter Benjamin, on a l'intention d'examiner comment les notions de critique, d'anachronisme, d'alégorie, d'image, de ruine, d'origine et de temps présent dialoguent et interagissent pour constituer des noyaux de réflexion.

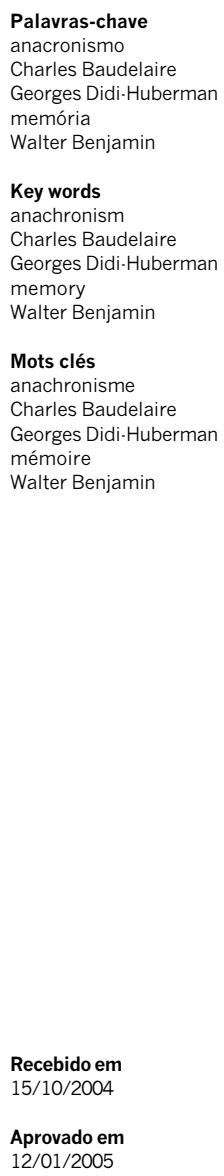

